\title{
Assessing the Military Impact of Capability Enhancement with Netlogo using the Falklands War as a Case-Study
}

\author{
Gowlett, $\mathbf{P}$. \\ Joint and Operations Analysis Division, Defence Science and Technology Organisation \\ Email: phillip.gowlett@dsto.defence.gov.au
}

\begin{abstract}
Military operations generating joint effects present significant complexity, often being comprised of large numbers of varied actors with competing goals operating across varied complex environments. This gives rise to the need to consider large combination sets when applying analytic techniques. The combination of modern, flexible and powerful agent-based models, computational search techniques and modern cluster computing promise faster, more efficient and accessible representation and exploration of parameter spaces and fitness landscapes of complex problems. We wish to apply these techniques to joint operations analysis, concept exploration and testing, joint capability analysis, emerging technology assessment and force structure analysis to enhance the quality and completeness of military planning.
\end{abstract}

Netlogo is a widely used agent-based modelling environment. This paper explores the feasibility of using Netlogo to build agent-based models to support operations analysis. A key objective of this study is to investigate the suitability and capability of Netlogo to represent military scenarios and to establish validity by way of reproducing historically documented operational dynamics and outcomes. To accomplish this, a scenario was constructed based on the air battles that occurred throughout the $21^{\text {st }}$ of May 1982 in the Falklands War. This scenario is appropriate as the conflict is well documented and amenable to analysis. A historical 'baseline' case was successfully modeled, analysed and validated against historical analysis, and a number of technology insertion cases have been modeled. The modelling allowed for the generation of quantitative metrics that compare how operational effectiveness and operational risk were affected by capability enhancement.

Keywords: Netlogo, agent-based, operations analysis 
Gowlett, Assessing the Military Impact of Capability Enhancement with Netlogo using the Falklands War as a Case-Study

\section{INTRODUCTION}

The Australian Defence Force (ADF) looks to the Defence Science and Technology Organisation (DSTO) to lead in the identification and assessment of emerging technologies that offer advantages or represent threats to ADF operations. Modelling approaches are of interest to develop analytic methods as an alternative or complement to qualitative assessment, and expert opinion. Availability of increased computing power at reduced costs provides a readily available increasing resource to analysts. In the interests of better harnessing this resource we are investigating the applicability of agent-based models, cluster computing, data mining and computational search techniques to operations analysis problems.

An early landmark in the use of some of these techniques in a military context was the Marine Corps Warfighting Laboratories Project Albert. From its inception in 1998, Project Albert employed data farming techniques, agent based distillations and supercomputers as a means to understand the landscape of a military problem space (Brandstein, 1998). DSTO analysts participated in this project and have subsequently applied a range of agent based models to a variety of operations analysis problems (Project Albert Website).

Netlogo was used by Wheeler (2005) to examine the interaction between civilian populations, guerrilla forces and peacekeeping forces. Dekker (2005) used an agent-based model developed in java to study the impact of network topology on military combat performance. Wheeler (2006) employed a custom developed agentmodel, genetic algorithms and game theory to derive insights into the importance of diversity and specialisation within combined arms teams.

Chandran (2009) provides support for the use of low complexity simulations to investigate particular types of military operations analysis problems. Importantly it was noted that such suitability is dependent on the question being asked and the defendable assumptions that can be made.

Building upon this experience, we wish to apply such methodology to the analysis of concepts of operation as affected by the employment of emerging technologies.

\section{MODEL CONSIDERATIONS}

The modelling requirements in no particular order are: parallel batch processing via cluster computing, representation of complex adaptive systems, scalable fidelity, flexible scripting environment, visualization, ease of use, low resource requirements (cost, manpower), and easy interfacing with data analysis tools.

Netlogo is a free to use agent-based modelling environment developed by Wilensky (1999) at Northwestern Universities Centre for Connected Learning. Netlogo has been the model of choice for hundreds of peer reviewed publications since 1999 across a range of fields. Netlogo is acknowledged as being relatively easy to use, well documented, flexible, and compatible with data farming and cluster computing methods (Koehler, 2005). Netlogo has emerged as a popular modelling environment for researchers across a number of fields in recent years (see Figure 1).

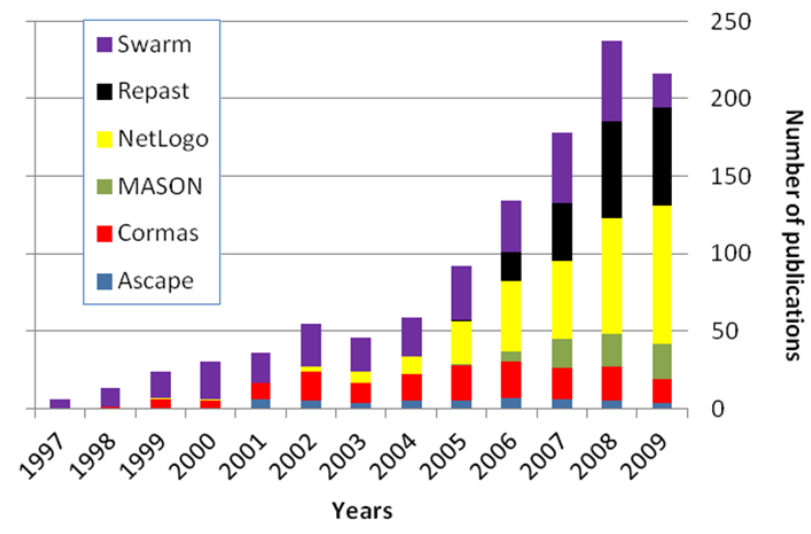

Figure 1: Agent-based model publications (Page, 2012)

In 2005 Wheeler evaluated Netlogo for its usefulness and suitability for modelling guerrilla warfare. Wheeler reports that the approach proved valuable for conducting preliminary studies with minimal time and effort and is amenable to higher fidelity studies. In 2008, Berryman reviewed a range of agent-based models for analysis of structure formation and causality in networks and reported favorably on Netlogo. Berryman found that:

- Netlogo was simpler to use but that networked communications were awkward to implement.

- Netlogo is a good environment for exploring structure formation.

- For those who aren't interested in networked causality, Netlogo is highly recommended.

On this basis it was decided to employ Netlogo as the agent based modelling environment, cognisant of the potential limitations noted by Berryman. 
Gowlett, Assessing the Military Impact of Capability Enhancement with Netlogo using the Falklands War as a Case-Study

\section{CASE STUDY: FALKLANDS WAR AIR BATTLES ON THE $21^{\mathrm{ST}}$ MAY, 1982}

The scenario case study chosen is a series of air battles that took place during the day following the British amphibious landing at San Carlos Water during the Falklands War. The morning following the British landing, Argentina launched some 40 attack sorties from three airbases on the Argentinean mainland. Throughout the day, British forces defended the amphibious task force against these sorties with six frigates, a destroyer, and 25 sea harriers that operated from two British aircraft carriers stationed east of the Falklands. Throughout the day, losses of men and equipment were significant on both sides (Smith, 1989; Battle Atlas of the Falklands War 1982 by Air, Land and Sea).

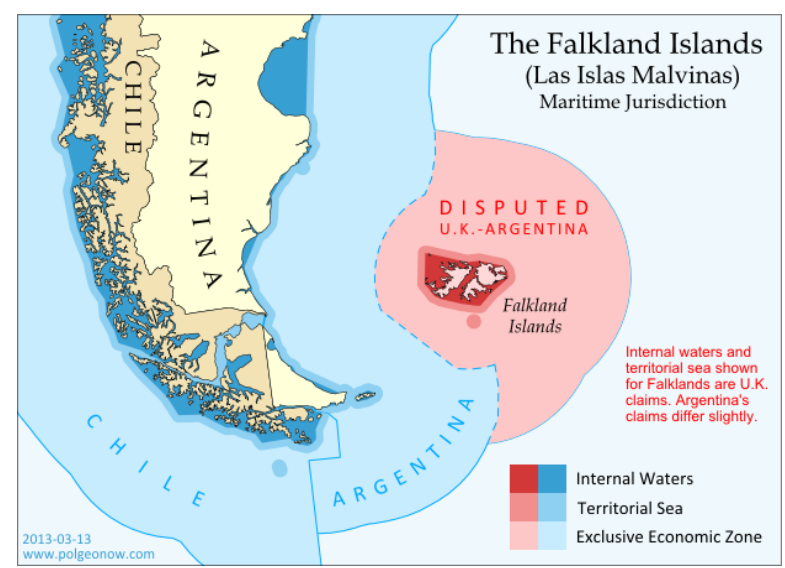

Figure 2: Falkland Islands (credit: www.polgeonow.com)

The key features and dynamics represented in the model are:

- Argentinean attack groups, operating from air bases on the Argentinean mainland.

- Combat air patrol by British Sea Harriers operating from British Carrier Battle Group.

- British amphibious fleet and escorts.

- Time, distance, mobility, endurance, detection, information sharing and weapon effects.

After base-lining the model to reproduce results consistent with historical outcomes, post-war analysis of the Falklands and subsequent military technology development provide inspiration for a number of "what-if" modelling cases. Below are descriptions of the modelling cases that were investigated.

\subsection{Validated historical baseline}

The initial model runs were used for the purpose of calibrating the model to historical evidence by adjusting parameters to ensure a number of key measures of effect matched (see Section 4). Most of the parameters were set from historical research. Initial runs demonstrated the lethality of the Sea Harriers was too high. Reducing the detection range of the Sea Harriers brought the model into alignment with historical figures. On inspection the calibrated range was found to be surprisingly short, but an explanation for this is provided by DeHoust (1984) (see Section 3.2). This checking of parameter appropriateness is considered to have provided a degree of model validation. Further model validation was conducted by modelling engagements that occurred on the on $12^{\text {th }}$ and the $25^{\text {th }}$ of May, 1982.

\subsection{A Sea Harrier Bluefox upgrade}

Low altitude approaches by Argentinean jets exploited a weakness of the Bluefox radar of the Sea Harriers, forcing harrier pilots to employ visual look-down shoot-down tactics (DeHoust, 1984). After the war, Bluefox radars were upgraded to improve performance at low altitudes in cluttered environments. What if the Bluefox radars were effective at the Falklands? This is represented in the model by doubling the range at which Sea Harriers detect Argentinean aircraft (see Figure 3).

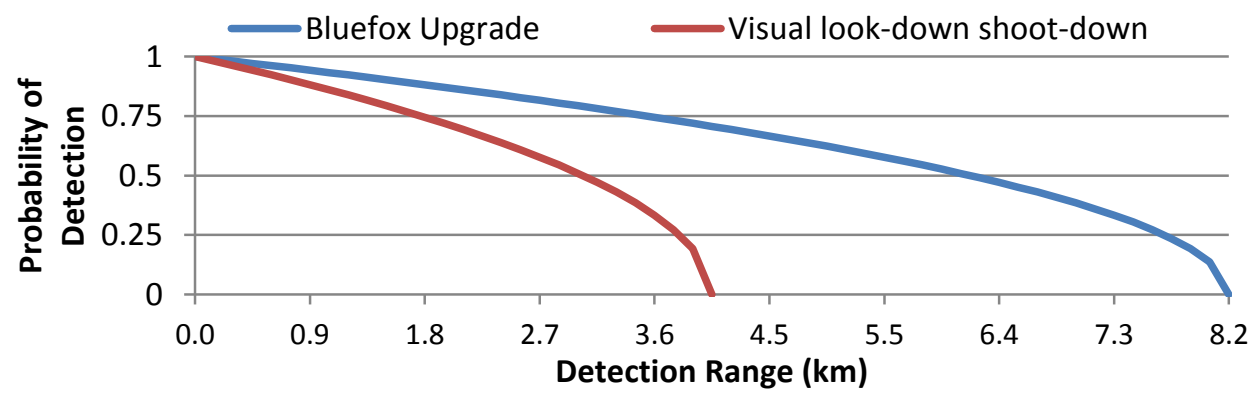

Figure 3: Comparison of visual look-down shoot-down as used in historical run and radar look-down shootdown as per Bluefox upgrade run. Vertical axis is probability of detection; horizontal axis is range in kilometers. All agents use a parabolic detection model. 
Gowlett, Assessing the Military Impact of Capability Enhancement with Netlogo using the Falklands War as a Case-Study

\subsection{A joint fires concept}

During the Falklands War, the island terrain and low altitude approaches made by Argentinean aircraft made it difficult for the British fleet to detect incoming threats and to lock their missile systems onto targets. What if airborne assets such as the Sea Harriers could hand-off targetting data to the British fleet? Such a capability allows platforms to share contacts and engage targets outside their detection range.

The joint fires (whole of force coordination of attack) concept is implemented in the model by allowing British agents to contribute to a contact list. All British agents then inspect this list for targets within their radius of concern. This allows Sea harriers to divert to bring nearby contacts within engagement range even if they cannot directly detect them. No delay or throughput limitation on the joint fires system has been implemented. Information sharing and target engagement can take up to one model tick or between 0-30 scale seconds after a contact is sighted.

\subsection{A ground-based fire-control radar}

After the war, the British retrofitted Sea King helicopters to carry an early warning radar to extend radar coverage in order to prevent a repeat of the Sheffield sinking (McComas, 1998). As a proxy, a ground-based fire-control radar is inserted that hands off targetting data to the British fleet and the sea harriers. The radar is given a maximum detection range of $72 \mathrm{~km}$. Operationally, such a system would have been a primary target for Argentinean forces and thus at extreme risk in a forward position. The radar is positioned on a bluff overlooking the British amphibious landing point at San Carlos Water where it can be afforded some protection by Sea Harriers on combat air patrol and British anti-air defences.

\subsection{Bombs that explode}

During the day, Argentinean jets, employed extremely low altitude (50ft) bombing tactics to avoid British anti-aircraft defences. As a consequence the bombs dropped did not have time to arm and rarely exploded. This is thought to have spared a number of British ships from catastrophic damage. What if ships hit by bombs had an $85 \%$ chance of being disabled or sunk? How does this affect the outcome?

\section{MODEL DESIGN}

Table 1: An overview of the parameters of an agent depicting an Argentinean A-4 Skyhawk awaiting takeoff from the San Julian air base.

\begin{tabular}{|c|c|}
\hline $\begin{array}{c}\text { Agent } \\
\text { Parameters }\end{array}$ & $\begin{array}{c}\text { Values for an } \\
\text { Argentinean } \\
\text { Attack Aircraft }\end{array}$ \\
\hline type & 2 \\
\hline side & $\mathrm{a}$ \\
\hline speed & 0 \\
\hline sight & {$[62]$} \\
\hline can-see & {$[02]$} \\
\hline range & {$[0.330]$} \\
\hline pk & 0.25 \\
\hline ammo & 1 \\
\hline max-fuel & 185 \\
\hline fuel & 185 \\
\hline 2D coordinates & {$[-44,-18]$} \\
\hline fleet & 3 \\
\hline
\end{tabular}

respect to scenario.
Aspiring to keep simulation complexity low and run times to a fraction of a minute, a 2D model was deemed appropriate. An agent 'type' property is used to restrict agent interaction between particular types and terrain. 'Types' include: -1 (sub-surface), 0 (surface), 1 (land), 2 (low flyer), 3 (high flyer). Agents are represented with MIL-STD2525B symbology as seen in Figure 4.

The model contains 84 agents, each described by up to 16 parameters (see Table 1). A significant fraction of time with regard to the body of work was required to research agent parameters to adequately represent British and Argentinean forces and their employment. Topographic effects are encoded into agent detection and weapon performance. The reasoning being that such effects were encoded into historical outcomes of the sorties - on which the agent parameters have been based. It is important to note that this constrains the use of particular agent parameters with

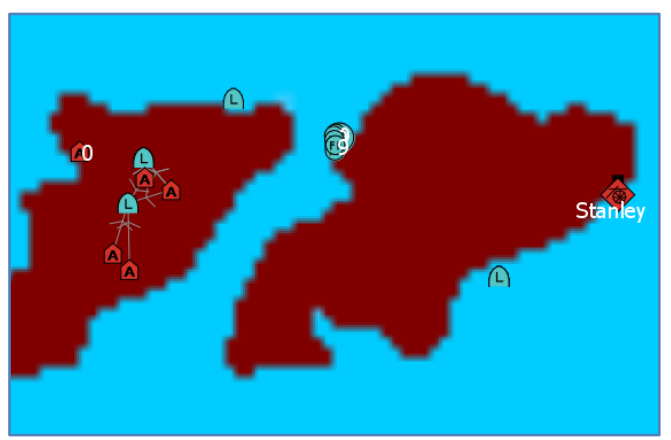

Figure 4: Model visualisation showing Sea Harriers (L) patrolling the Falklands for Argentinean attack aircraft (A). An escort comprising of frigates (FF) and a destroyer screen the amphibious fleet at San Carlos Water. Directional links show what agents are visible to others. 
Gowlett, Assessing the Military Impact of Capability Enhancement with Netlogo using the Falklands War as a Case-Study

Each time-step (tick) is a scale 30 seconds. This ensures that the maximum relative movement of agents remains comparable to minimum agent interaction distances. Agent positioning is handled with continuous coordinates. Each tick the agents build a list of contacts. Contacts within range are designated as targets and engaged in order of proximity. Built-in Netlogo functionality ensures agent turn order is random.

Argentinean aircraft sorties are historically accurate down to the departure time, formation size and number. Sea Harrier patrols are historically representative as exact sortie times were not available.

Over modelling runs three global parameters are monitored as key operational measures of effectiveness: total bombing attacks by Argentinean attack aircraft against British targets, total bomb hits on British targets, and total Argentinean aircraft losses. Each modelling case is run 480 times to ensure statistically relevant data is collected while keeping run times under 10 minutes.

\section{RESULTS}

Below on the left are the model validation results. The scenario within which the technology insertions are investigated is shown in the middle $\left(21^{\text {st }}\right.$ May) bracketed above and below by the two validation runs which modeled different engagements occurring on the $12^{\text {th }}$ and $25^{\text {th }}$ of May. Below on the right are the results of the technology insertion 'what if' cases described in Sections 3.2 through 3.4

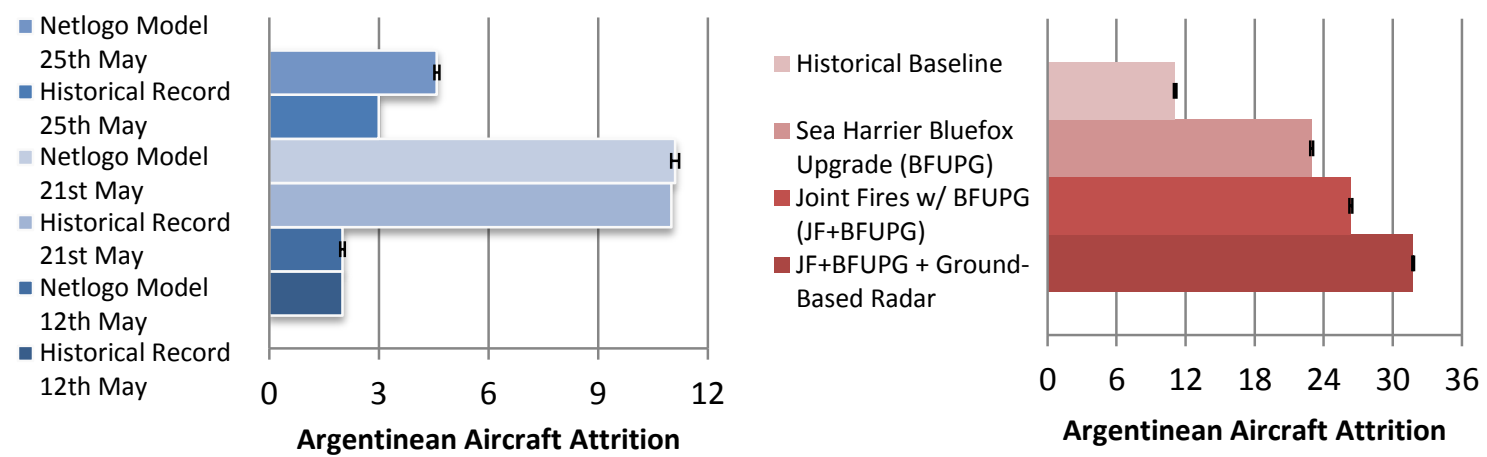

Figure 5: Operational measure of effect 1 - mean Argentinean aircraft shot-down by British forces.
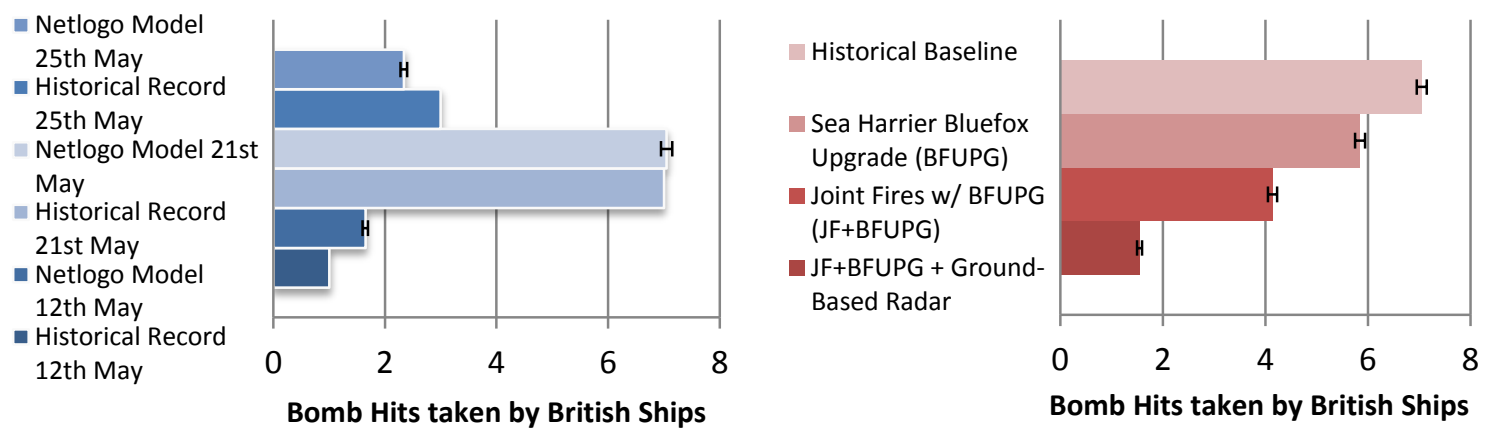

Figure 6: Operational measure of effect 2 - mean bomb hits scored by Argentinean aircraft on British targets.
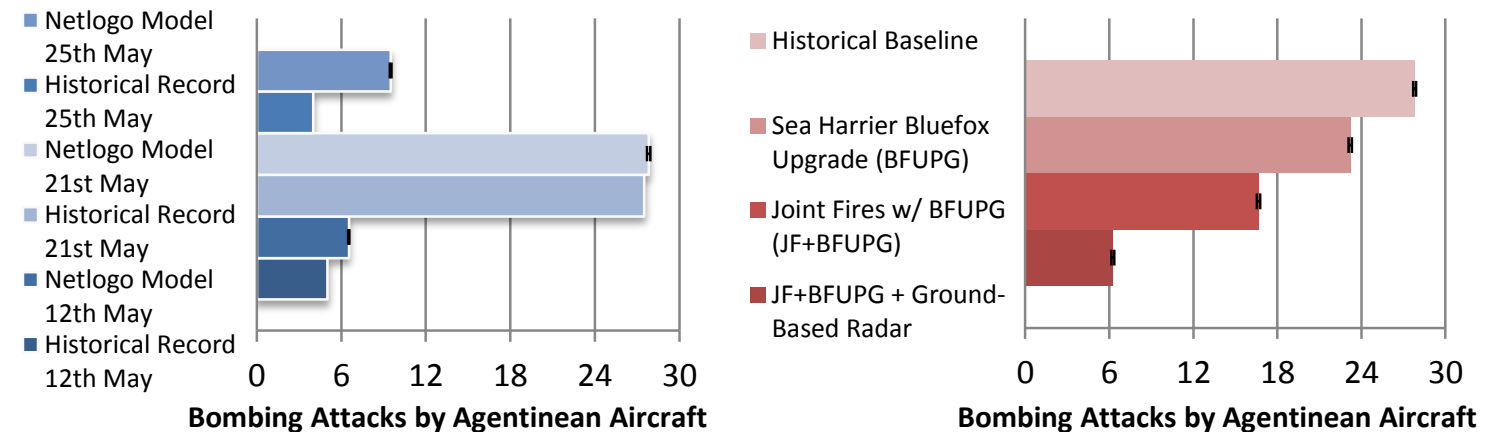

Figure 7: Operational measure of effect 3 - mean bomb attacks by Argentinean aircraft on British targets. 
Gowlett, Assessing the Military Impact of Capability Enhancement with Netlogo using the Falklands War as a Case-Study

The model validation is viewed as supportive particularly with regard to Argentinean aircraft attrition (Figure 5 ) and bomb hits on British ships (Figure 6). The number of bomb attacks on the $25^{\text {th }}$ of May (Figure 7) showed the greatest deviation from historical figures (138\%). Contextual differences between the validation scenarios makes some degree of variation inevitable, however the magnitude in this case suggests that the routines controlling Argentinean aircraft agent decision making may not be sufficiently flexible.

Looking at the technology insertion 'what if' results, it is seen that the Sea Harrier Bluefox upgrade had the effect of more than doubling Argentinean aircraft attrition to $62 \%$ (from Figure 5), while cutting their sortie success rate by approximately one-third to $15.8 \%$ (see Figure 6). The joint fires concept resulted in a further $40 \%$ reduction in the sortie success rate to $11.9 \%$ (see Figure 6). Argentinean aircraft attrition increased by $15 \%$ to $71.3 \%$ (see Figure 5), which was less than expected and thought to be the result of probable Sea Harrier intercepts prevented due to a lack of ammunition. Addition of the early-warning fire-control radar increased the attrition rate of Argentinean attack aircraft by a further $20.5 \%$ to $85.9 \%$ (see Figure 5) by increasing the effectiveness of British surface-to-air missile defences. As a result, the Argentinean sortie success rate consequently collapsed to $4.2 \%$ (see Figure 6). Error was estimated using the standard error of the mean: $\frac{s}{\sqrt{n}}$, where $\mathrm{s}$ is the sample standard deviation, and $\mathrm{n}$ is the sample size.
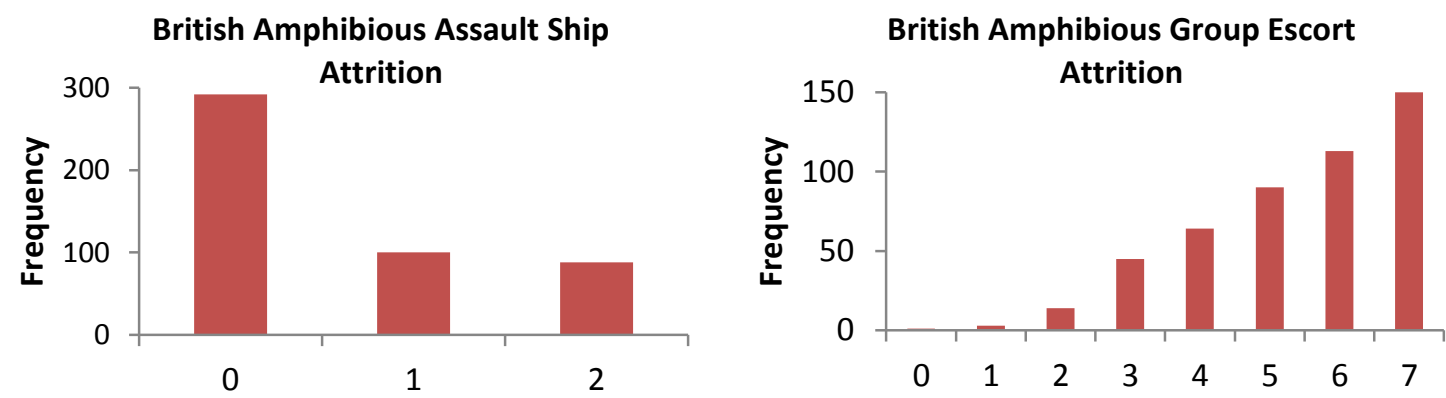

Figure 8: Histogram results of model runs in the case of 'bombs that explode' (see section 3.5). (Left) Histogram of British amphibious ships bombed. (Right) Histogram of British escorts (one destroyer, six frigates) bombed by Argentinean aircraft. Histogram data points: 480.

In Figure 8, it is seen that Argentinean bombs fused in a manner suited to extremely low altitude releases (as per section 3.5) result in a $40 \%$ chance of at least one amphibious assault ship being taken out. The British amphibious escorts do not fare well at all, with an attrition rate of $77.4 \%$, versus a historical figure of $28.6 \%$ (one sunk, two seriously damaged - one remained operational) (Battle Atlas of the Falklands War 1982 by Land, Air and Sea).

\section{CONCLUSIONS}

The Netlogo modelling conducted was successful in supporting the production of metrics that quantify changes in operational risk as a result of capability enhancement. A number of interesting cases that could be investigated with simple extensions to the model were also identified:

- The joint fires results hint at the possibility of further interceptions if Sea Harriers were able to carry more ammunition. This could be investigated with further analysis looking at the effect of trading off fuel for additional AIM-9L missile(s).

- An extension to the joint fires modelling that could be easily investigated is the effect of varying information throughput and latency across the joint fires network.

- The operational validity of the early-warning fire-control radar results depend on the survivability of the radar; promoting a more survivable airborne implementation. It then follows that trading-off Sea Harriers for airborne early warning and control aircraft may be worthwhile investigating, assuming such aircraft (for example Northrop Grumman Hawkeye) could be operated off the British carriers.

Validation runs suggest that coding a routine into Argentinean aircraft agents that causes them to abort their mission if a wingman is lost on approach could enhance realism, allowing better fitting to historical data.

Netlogo was found to have demonstrated adequate capability and excellent useability in the context of the case study evaluated. The short time-frames within which such Netlogo models can be developed is deemed to be a key asset. Visualisation was simple to use, yet useful for verifying agent behavior, demonstrating the model and debugging the model. Most code was generally easy to write, with occasional effort required to devise a solution where an appropriate function does not exist. Modifying the model and running batches was 
Gowlett, Assessing the Military Impact of Capability Enhancement with Netlogo using the Falklands War as a Case-Study

very straight-forward with BehaviourSpace or via Java. The concerns raised by Berryman (2008) over the clarity with which methods are associated with agents in Netlogo was not seen as a problem in the development of this model. Berryman's assessments of Netlogo concerning networked causality only appear valid provided that one does not utilise the Java API to implement agent learning.

With the backing of defendable agent and system models such modelling is thought suitable for first pass quantitative assessment of emerging technology impact, as well as concept development and testing. Future work to integrate software that facilitates the conduct of sensitivity analysis, search, optimisation, coevolution and automated data analysis and interpretation will improve the capability and efficiency of Netlogo as an analysis tool in the context of military operations. Running Netlogo across a computer cluster is a future goal as it will allow for greater levels of simulation complexity while retaining low run times. Cluster computing is viewed as a requirement for practical implementation of evolutionary learning in Netlogo. By leveraging such functionality, it is envisaged that the case study will be revisited with the addition of intelligent mission planners that can evolve new tactics for the employment of Argentinean and British forces.

\section{ACKNOWLEDGEMENTS}

The author would like thank Dr Tony Dekker for sharing his knowledge of agent-based modelling and encouraging this work in its initial stages.

\section{REFERENCES}

Battle Atlas of the Falklands War 1982 by Land, Sea and Air, http://www.navalhistory.net/NAVAL1982FALKLANDS.htm accessed June 2013

Berryman, M. (2008). Review of Software Platforms for Agent Based Models, DSTO-GD-0532, April 2008

Brandstein, A and Horne, G. (1998). Data Farming: A Meta-technique for Research in the 21st Century, Maneuver Warfare Science 1998, US Marine Corps Combat Development Command Publication, http://www.projectalbert.org/files/data farming.pdf

Chandran, A. (2009). Modelling Maritime Surveillance - Is Complexity Worth It? 18th World IMACS / MODSIM Congress, Cairns, Australia 13-17, July 2009

DeHoust, W. (1984). Offensive Air Operations of the Falklands War, Marine Corps Command and Staff College, 1984

Dekker, T. (2005). Network Topology and Military Performance, n Zerger, A. and Argent, R.M. (eds), MODSIM 2005 International Congress on Modelling and Simulation, Modelling and Simulation Society of Australia and New Zealand, December, 2174-2180, 2005 http://www.mssanz.org.au/modsim05/papers/dekker.pdf

Koehler, M., Upton, S., and Tivnan, B. (2005). Clustered Computing with NetLogo and RepastJ: Beyond Chewing Gum and Duct Tape. Proceedings of Agent 2005. Argonne National Lab, Chicago, IL., 2005

McComas,. (1998). Beyond the General Belgrano and Sheffield: Lessons in Undersea and Surface Warfare from the Falklands Islands Conflict, Naval Science 2 - Research Paper, MIDN 4/C Swartz, April 1998

Page, C., Becu, N., Pierre, B. et al. (2012). Participatory Agent-Based Simulation for Renewable Resource Management: The Role of the Cormas Simulation Platform to Nurture a Community of Practise, Journal of Artificial Societies and Social Simulation 15 (1) 10, 2012

Project Albert Website, http://www.projectalbert.org/ accessed 5/2013

Smith, G., (1989). Battles of the Falklands War, Published by Allen (Ian) Ltd

Wheeler, S. (2005). It Pays to be Popular: A Study of Civilian Assistance and Guerrilla Warfare, Journal of Artificial Societies and Social Simulation, Vol 8, No 4 October 2005

Wheeler, S. (2006). An analysis of combined arms teaming for the Australian Defence Force, Journal of the Operational Research Society (2006) 57, 1279-1288

Wilensky, U. (1999). NetLogo. http://ccl.northwestern.edu/netlogo/. Center for Connected Learning and Computer-Based Modeling, Northwestern University. Evanston, IL. 